\title{
MEMÓRIA DA ESCRITA E ESCRITA DA MEMÓRIA
}

Marcia Cristina Corrêa

GRPESQ/ CNPq Discurso, História, Gênero e Identidade

Neste artigo, pretendemos discutir alguns conceitos pertinentes à proposta do Corpus : Laboratório de Fontes de Estudos da Linguagem e relacionados à perspectiva de nosso trabalho.

Dessa forma, serão discutidos os conceitos de memória, identidade e escrita. Para isso, tomaremos por base textos de Platão, Vygotsky e Bourdieu.

\section{MEMÓRIA E ESCRITA}

Para começar a discutir a relação que se estabelece entre os conceitos de memória e de escrita, adotamos uma passagem de Fedro, de Platão, considerada clássica sobre o assunto. O trecho diz respeito ao diálogo entre o deus Thoth (que inventou a escrita) e 0 deus Tamuz (rei de Tebas, do Egito):

Thoth:

Esta arte, caro rei, tornará os egípcios mais sábios e Ihes fortalecerá a memória; portanto, com a escrita inventei um grande auxiliar para a memória e a sabedoria.

\section{Tamuz:}

Tu, como pai da escrita, esperas dela com o teu entusiasmo precisamente o contrário do que ela pode fazer. Tal cousa tornará os homens esquecidos, pois deixarão de cultivar a memória; confiando apenas nos livros escritos, só se lembrarão de um assunto exteriormente e por meio de sinais, e não em si mesmos. Logo, tu não inventaste um auxiliar para a memória, mas apenas para a recordação. Transmites aos teus alunos uma aparência de sabedoria, e não a verdade, pois eles recebem muitas informações sem 
instrução e se consideram homens de grande saber embora sejam ignorantes na maior parte dos assuntos. Em conseqüência serão desagradáveis companheiros, tornar-se-ão sábios imaginários ao invés de verdadeiros sábios (Platão,1962:35). (grifos meus)

Nessa passagem do diálogo de Platão, o contraditório se estabelece, ou seja, a escrita que é inventada para auxiliar a memória dos homens, torna-os esquecidos. Em princípio essa relação parece muito estranha, visto que, comumente se diz que quem tem boa memória é aquele que não esquece.

Então, de que esquecimento estaria falando o rei de Tebas? A que tipo de memória estaria se referindo? A fim de desvendar esse estranhamento, pretendemos discutir um pouco mais a fundo essas questões. Para tanto, iniciamos, lançamos um olhar vygotskiano sobre a relação entre memória e escrita.

Para Vygotsky, ao longo da história humana, há dois tipos de memória : a natural e a mediada. O primeiro tipo de memória é caracterizado pela "impressão não mediada de materiais, pela retenção das experiências reais como base dos traços mnemônicos" (1998:52). O segundo tipo, diz respeito a processos psíquicos mais elaborados, que fazem uso de recursos (os mais diversos) para irem além dos limites das funções psicológicas impostas pela natureza. Nesse sentido, esses recursos modificam a estrutura psicológica do processo de memória, pois estendem a operação da memória para além das dimensões biológicas do sistema nervoso humano, "permitindo incorporar a ele estímulos artificiais, ou autogerados, que chamamos de signos" (1998:52). Para o autor, signo é aquilo que pode ser interpretável como representação da realidade e pode referir-se a elementos ausentes do espaço e do tempo presentes.

Essa capacidade de mediação simbólica representa uma nova forma de comportamento, que abarcaria as atividades que 0 autor denomina de funções psicológicas superiores. A estrutura das referidas formas superiores de comportamento - operações com signos - requer um elo intermediário entre o estímulo e a resposta. Esse elo intermediário é concebido como um estímulo de segunda ordem - signo - colocado no interior da operação, onde preenche uma função especial : ele cria uma nova relação entre o estímulo e a resposta. Além disso, cumpre destacar que o signo possui a importante característica de ação reversa, isto é, ele age sobre o 
indivíduo e não sobre o ambiente. Desta forma, o processo simples estímulo - resposta é substituído por um ato complexo, mediado.

Segundo Oliveira(1998), ao longo da história da espécie humana, as representações da realidade têm se articulado em sistemas simbólicos. A partir disso, Vygotsky (1998) considera a linguagem como o sistema simbólico fundamental em todos os grupos humanos, elaborado no curso da história social, que organiza os signos em estruturas complexas e desempenha um papel imprescindível na formação das características psicológicas humanas.

Dessa forma, o domínio da linguagem promove três mudanças fundamentais nos processos psíquicos humanos:

$>$ A linguagem permite lidar com os objetos do mundo exterior mesmo quando eles estão ausentes.

> A linguagem possibilita o processo de abstração e generalização.

$>$ A linguagem tem função de comunicação entre os homens, garantindo a preservação, transmissão e assimilação de informações e experiências acumuladas pela humanidade ao longo da história.

Além dos aspectos referidos, é importante ressaltar que Vygotsky (1998) considera que, através da mediação simbólica, os processos de funcionamento mental do homem são fornecidos pela cultura. Cumpre lembrar que cultura, para Vygotsky, não é algo acabado, um sistema estático ao qual o homem se submete simplesmente. Pelo contrário, cultura, para ele, é uma espécie de palco de negociações, onde os indivíduos interagem constantemente no sentido de recriar reinterpretar informações, conceitos e significados.

Tudo isso é realizado a partir do momento em que a criança aprende a linguagem do seu grupo social, e, através dela, passa a dominar os aspectos culturais e as regras sociais da sua comunidade. Nesse sentido, 0 homem se constitui sócio e culturalmente através da linguagem.

Para o autor, a conquista da linguagem representa um marco no desenvolvimento humano. Ele destaca que os signos e as palavras têm, como função primordial, mediar o contato com as 
outras pessoas, e, dessa forma, as funções cognitivas e comunicativas da linguagem constituem a base de uma forma nova e superior de atividades nas crianças. A partir do exposto, podemos dizer que a linguagem tanto expressa o pensamento da criança como age como organizadora desse pensamento.

Ao explicitar o processo da relação entre pensamento e linguagem, Vygotsky (1998) reafirma que a função primordial da fala é o contato social, entendendo que o desenvolvimento da linguagem é impulsionado pela necessidade de comunicação e mesmo a fala mais primitiva da criança tem o caráter social.

Já a escrita, para Vygotsky (1998), desempenha papel fundamental no desenvolvimento cultural da criança. Para o autor, a escrita é um sistema complexo que constitui um simbolismo de segunda ordem, que, gradualmente, transforma-se em simbolismo direto. Em princípio, entre os signos da escrita e as relações e entidades reais, haveria um elo intermediário: a linguagem falada. Nesse sentido, a escrita inicial representaria a fala e não os eventos da realidade. Num segundo momento, 0 elo intermediário desapareceria, isto é, os signos da linguagem escrita passariam a estabelecer uma relação direta com as entidades reais.

Ao tratar do simbolismo da escrita, o autor faz referência às formas primitivas as quais incluiriam os rabiscos que, inicialmente, não teriam nenhuma função auxiliar para a memória, até 0 momento em que esses traços se tornam símbolos mnemotécnicos. $\mathrm{O}$ autor considera esse estágio como o primeiro precursor da futura escrita.

Nesse estágio, os sinais constituem símbolos de primeira ordem, isto é, representam diretamente objetos ou ações. Todavia deverão evoluir no sentido de constituir um simbolismo de segunda ordem, que pode ser considerado como a criação de sinais que representam os símbolos falados das palavras. O autor destaca que, para isso: "a criança precisa fazer uma descoberta básica - a de que se pode desenhar, além de coisas, também a fala". E acrescenta que "foi essa descoberta, e somente ela, que levou a humanidade ao brilhante método da escrita por letras e frases; a mesma descoberta conduz a criança à escrita literal" (1998:153).

Em síntese, podemos afirmar que, para Vygotsky, o desenvolvimento da linguagem escrita na criança se dá pelo deslocamento do desenho de coisas para o desenho de palavras. $E$, a partir disso, para ele, o segredo do ensino da linguagem escrita estaria na preparação e organização dessa transição. O autor 
salienta, ainda, que a transição ocorre de uma maneira natural. Dessa forma, a criança passaria a dominar os princípios da linguagem escrita, restando, apenas, aperfeiçoá-la.

Para Vygotsky, o aprendizado da escrita é considerado como um momento de passagem para um estágio avançado da formação do pensamento lógico e, com isso, a concretização dos processos mentais superiores. Da mesma forma, com a escrita, a criança estaria pronta para dar conta de um novo tipo de conhecimento: o conceito científico ou escolarizado.

Em síntese, nas idéias de Vygotsky, os conceitos de memória e escrita parecem fortemente ligados. Uma vez que a memória mediada tem como principal elo intermediário um sistema simbólico (signos), esse, por sua vez, tem na linguagem sua expressão maior. Como o autor considera a escrita como sendo a forma mais complexa de linguagem, a memória encontra na escrita o seu principal auxiliar.

Dessa forma, as idéias de Vygotsky confirmam a expectativa gerada em princípio e levam a negação do pensamento do rei de Tebas sobre a escrita provocar o esquecimento. Se pretendêssemos buscar uma resposta rápida e tranqüilizadora, concordaríamos de imediato com esse raciocínio. Mas, como nos propomos a analisar a fundo as questões, isso não basta. Precisamos acrescentar mais alguns elementos nesta reflexão, para então esboçarmos algumas possíveis respostas para as questões.

\section{ORALIDADE E ESCRITA}

Tomemos para discussão as perspectivas de estudo da linguagem adotadas por Vygotsky: a filogênese e a ontogênese, ou seja, ele analisa a linguagem tanto na sua evolução histórica (espécie) quanto na evolução do indivíduo. Assim, para ele, tanto o surgimento da linguagem na história da humanidade quanto à aquisição da linguagem (fala) pela criança têm a mesma origem : a necessidade da interação social. No aspecto histórico, diz respeito à necessidade de intercâmbio no trabalho, no individual, refere-se à necessidade de interação com os membros do grupo social a que pertence. Em ambos os casos, há um processo considerado pelo autor como natural. 
Com relação à escrita, podemos identificar traços comuns entre as duas perspectivas. Na filogênese, tivemos a necessidade de registrar informações, para não perde-las, e de passa-las para as gerações futuras. Nesse percurso o homem passou por uma história que vai desde desenhos, rabiscos até os diferentes sistemas que temos hoje. Na ontogênese, esse processo não será igual para todas as crianças, isto é, a necessidade da escrita na criança será motivada a partir da importância que esse sistema tem no grupo social ao qual a criança pertence. Se houver a necessidade da escrita, essa passará por diferentes estágios, que se aproximam daqueles superados no âmbito histórico.: desenhos, rabiscos, símbolos até chegar ao sistema de escrita. O processo que pauta a escrita, nas duas perspectivas, é considerado por Vygotsky como artificial.

Em síntese, para ele, a aquisição da escrita não ocorre da mesma forma que a aquisição da oralidade. Salienta que, na oralidade, a aquisição se dá de uma forma natural, desenvolvida pela própria criança, enquanto na escrita, há um procedimento artificial, visto que o processo exige um treinamento tanto do aluno quanto do professor.

Dessa forma, o autor nos remete a um rompimento - de processo natural para artificial - que haveria na aquisição da escrita. No nosso entender, é a partir desse rompimento que se torna possível fazer uma relação com o texto de Platão, a fim de compreender a que esquecimento se refere o autor.

Para fazermos uma busca da referência do esquecimento de Platão, devemos iniciar uma incursão sobre a diferença que se estabelece na relação sujeito e linguagem, considerando as duas variedades: a oral e a escrita.

Cumpre lembrar que, para Vygotsky, a linguagem é a base para o entendimento das funções psicológicas superiores e, conseqüentemente, a pedra de toque para a compreensão do homem. Para Vygotsky, a linguagem é vista como lugar de interação e de interlocução, ao mesmo tempo em que constitui os pólos da subjetividade e da alteridade, é constantemente modificada pelo sujeito, que atua sobre ela.

Essa concepção permite não só visualizar uma relação dinâmica e constitutiva entre o sujeito e a linguagem, como também voltar a atenção para os sujeitos e suas histórias individuais de relação com a linguagem. Assim, dentro dessa concepção, os papéis de sujeito e de outro na linguagem adquirem relevância e, 
com isso, passam a interessar os indivíduos que ocupam esses papéis discursivos, em situações reais de interlocução, historicamente situadas.

\subsection{EU E O OUTRO NA ORALIDADE}

Com relação à aquisição da fala, há o que se poderia chamar de consenso entre as diferentes teorias; a criança adquire a fala/língua do seu grupo. Na perspectiva de Vygotsky, e aí acaba o consenso, o processo de aquisição se dará de forma natural, a partir das interações sócias dos membros do grupo.

A visão sócio-histórica da linguagem reafirma a direta relação - na verdade, uma via de duas mãos - entre língua e sociedade. Assim, ao constatarmos a complexidade de qualquer estrutura social, que tem como principal característica o convívio (ilusório) das diferenças : étnicas, culturais, religiosas, políticas, econômicas etc. Dessa forma, a partir da relação estabelecida entre (língua e sociedade), qualquer visão (sociológica) menos ingênua do conceito de língua, entende que a mesma não pode ser compreendida como um bloco fechado, uma unidade, mas sim um conjunto de variedades que a compõe (Como nos dizem os trabalhos de Labov)

$\mathrm{Na}$ fala/ oralidade é que temos a consciência da diferença, da variação. Essa consciência decorre da referência que o sujeito tem da fala/ língua do seu grupo, pois a partir da sua fala, na interação social, é que ele estabelece os parâmetros para a diferença. Em outras palavras, a referência da minha fala está na oposição da fala do outro. Assim, o modo diferente de falar é uma peculiaridade que me distingue do outro, portanto, tenho uma idéia de identidade a partir desse jogo de oposição: eu (minha fala) e o outro (a fala do outro).

Em síntese, podemos dizer que, na fala, o jogo de oposição leva a uma identidade lingüística, que, na perspectiva teórica adotada, não diz respeito somente a um sistema de língua, mas sim a toda uma carga social, cultural, política, ideológica etc . Enfim, na fala e pela fala, o sujeito tem a sua marca de diferença, que nós poderíamos chamar de identidade.

E a memória? Bem, no nosso entender, a memória (cultural,social) é o que gera a identidade, sendo assim, a memória está marcada pela oralidade. 


\subsection{EU E O OUTRO NA ESCRITA}

A aquisição da escrita, diferentemente da fala, está vinculada a um espaço social restrito, ou melhor, o papel de ensinar a escrever é delegado, na nossa sociedade, à instituição escola.

A escola é um espaço social distinto, marcado pelo rompimento do cotidiano da criança, estabelecendo um contexto diferente daqueles já conhecidos pela criança. Com isso, ocorre uma mudança brusca, decorrente da quebra da espontaneidade ao aprender, pois, a partir daí, há uma série de novas responsabilidades atribuídas ao aluno, como o desempenho e a disciplina. A escrita, ou o aprender sistemático da escrita, entra na vida da criança nesse contexto.

No contexto escolar, a relação do sujeito com a linguagem é cerceada por um discurso pedagógico que visa legitimar um modelo de língua e de escrita. Na escola, a visão ingênua de língua, referida anteriormente, ou seja, enquanto unidade, encontra seu melhor campo para fortalecimento. Assim, o discurso sobre língua é pautado em um modelo considerado o correto, desqualificando toda e qualquer ocorrência lingüística diferente. Qual seria o modelo escolhido? É o modelo da língua normatizada (para Saussure) ou seria a língua de maior valor no mercado lingüístico instaurado na sociedade (para Bourdieu), ou simplesmente, a língua (conforme discurso corrente na mídia e no ensino).

Com relação a isso, Bourdieu faz o seguinte questionamento à cerca da visão (ingênua) da unidade lingüística. Para ele,

falar de a língua, sem qualquer outra especificação como fazem os lingüistas, é o mesmo que aceitar tacitamente a definição oficial da língua oficial de uma unidade política : nos limites territoriais desta unidade, esta língua é a que se impõe a todos os que pertencem àquela jurisdição como a única legítima, e de maneira tanto mais imperativa quanto mais oficial for a circunstância. Produzida por atores com autoridade para escrever, fixada e codificada pelos gramáticos e professores.(...) Ninguém pode ignorar a lei lingüística que dispõe de seu corpo de juristas (os gramáticos) e de seus agentes de imposição e de controle (os professores) (1996:31-32). 
Nas palavras do autor, fica evidente o papel do professor na imposição dessa "língua" aos seus alunos. Inclusive Bourdieu apresenta, de forma de crítica, quase satírica, uma passagem de um texto ${ }^{1}$ exaltando justamente essa tarefa atribuída ao professor:

Ele (o professor primário) age cotidianamente por força de sua função sobre a faculdade de expressão de qualquer idéia e emoção : sobre a linguagem. Ensinando a mesma língua (uma, clara e fixa) a crianças que só a conhecem de modo confuso ou que falam diversos dialetos e idiomas, ele faz com que se inclinem naturalmente a ver e a sentir as coisas da mesma maneira e assim trabalha para edificar a consciência comum da nação (1996:35). (grifos meus)

Esse trecho corrobora o papel fundamental do professor e do sistema escolar na imposição de uma língua (clara, una e fixa). Para Bourdieu o padrão de referência para a língua ensinada na escola está atrelado ao modelo da escrita. Nas palavras do autor, "O código que rege a língua escrita, identificada à língua correta, por oposição à língua falada, implicitamente tida como inferior, adquire força de lei no e pelo sistema de ensino."

Vejamos, impor uma língua (clara, una e fixa) representa fazer com que as crianças abandonem a referência de língua que tinham (inferior, modo confuso, dialeto). Portanto, devem abandonar a língua falada na sua comunidade (fora da escola) e devem assumir como sua a língua baseada no modelo escolar proposto.

A partir da imposição do modelo, cabe também ao professor fazer com que os alunos, que antes apresentavam histórias e culturas diferentes (baseadas nos referenciais da comunidade), "se inclinem naturalmente a ver e a sentir as coisas da mesma maneira", e assim trabalha para edificar a consciência comum da nação".

Portanto, o sistema escolar tem como objetivo estabelecer um ideal de unidade lingüística e unidade cultural e, para isso, tem como principal instrumento ${ }^{2}$ : a língua escrita.

Nesse contexto, como se dá a relação do sujeito como a linguagem?

Se na fala temos a consciência da diferença, pela oposição com a fala do outro, que marca a identidade; na escrita, ao contrário, a subjetivade da linguagem tende a ser anulada. Ainda se o que me 
identifica como sujeito é a minha (grupo) diferença, no processo escolar, principalmente, na relação com a escrita, o diferente é excluído (marginalizado) em prol do ideal de unidade lingüística (modelo de escrita) e cultural (daquele que escreve). Como, geralmente, não há coincidência entre a escrita e referencial cultural do sujeito e o padrão estabelecido para isso, decorre daí a imposição desses padrões provocando um estranhamento do sujeito com a escrita.

Na relação eu e outro na escrita, o eu é anulado, pois diz respeito às coisas que fogem ao modelo, seja lingüístico, seja cultural, o que prevalece é o outro.

E a memória? A memória, na escrita, diz respeito ao outro. Esse outro pode ser entendido como aquele que, na nossa sociedade, tem o poder de escrever e logo, por escrever, tem o poder. Com isso, fecha-se o círculo histórico-social da escrita e do poder.

\section{MEMÓRIA DA ESCRITA E ESCRITA DA MEMÓRIA}

Após as reflexões realizadas sobre memória e escrita, (Vygotsky e Bourdieu), voltemos as perguntas propostas a partir do texto de Platão. (Lembram-se delas? Como está a memória de vocês depois desse longo percurso ou divagação?)

A primeira: De que esquecimento estaria falando o rei de Tebas? "Tal cousa (a escrita) tornará os homens esquecidos".

Achamos interessante lembrarmos que escrever (como todo e qualquer ato de linguagem) é um processo seletivo, isto é, dentre várias possibilidades, algo é eleito para ser registrado.

A partir disso, analisando a escrita pelo prisma do que foi escrito, a escrita é registro, rastro, perpetuação. Já, analisando pelo aspecto do que não foi escrito, a escrita é um grande esquecimento.

Além disso, o acesso ao escrito nos torna "sábios imaginários", uma vez que o conhecimento do escrito, dá-nos a aparência de sabedores do todo. Assim, pior do que sábios imaginários e sermos "esquecidos" que, na verdade, somos sabedores do "escrito" do "outro".

Em síntese, temos a escrita da memória do outro, que passamos a adotá-la como sendo a nossa memória. referindo?

A segunda pergunta: A que tipo de memória estaria se 
Para entender a escrita como auxiliar da memória, só se estivermos nos referindo à capacidade biológica de memória humana : anotar, registrar para não esquecer. Quando nos referimos à memória, a partir das idéias de Vygotsky, entre elas a concepção de linguagem no sentido de lugar de interação e interlocução, o conceito de memória diz respeito à construção histórica e cultural de uma comunidade. Essa memória está viva na oralidade de seus integrantes. Na escrita, está a versão daquele que tem o poder para registra-la. Depois do registro, pela intervenção das instituições sociais (igreja e escola), passamos a ter a memória da escrita.

\section{NOTAS}

${ }^{1}$ DAVI,G. Élements de Sociologie. Paris: Vrin, 1950 (p.233).

${ }^{2}$ Conceito utilizado, propositalmente, no seu sentido estrito, da mesma forma que foi utilizado pela lingüística.

\section{BIBLIOGRAFIA}

BOURDIEU, Pierre. A economia das trocas lingüísticas. São Paulo: Edusp, 1996.

GNERRE, Maurizio. Linguagem, escrita e poder. São Paulo: Martins Fontes, 1994.

OLIVEIRA, Marta Kohl de. Vygotsky: aprendizado e desenvolvimento. Um processo sócio-histórico. São Paulo: Scipione, 1998.

PLATÃO. Diálogos: Mênon-Banquete-Fedro. Porto Alegre: Globo, 1962.

VIGOTSKI, L.S. A formação social da mente. São Paulo: Martins Fontes, 1998. 


\section{SOBRE A AUTORA}

Marcia Cristina Corrêa é professora de Língüística do Departamento de Letras Clássicas, Filologia e Lingüística da UFSM.

É mestre em Estudos da Linguagem - UFSM (1995), com a dissertação "Características fonético-fonológicas da língua portuguesa falada em Vale Vêneto - RS", sob a orientação da Prof ${ }^{a}$ Dr. Leda Teresinha Martins.

Atualmente desenvolve a tese de doutorado em aquisição da língua materna - escrita, na UFRGS, sob a orientação da Prof ${ }^{a}$ Dr. Ana Maria de Mattos Guimarães.

$\mathrm{Na}$ UFSM, orienta pesquisas referentes à escrita e coordena grupos de estudos com alunos de graduação em Letras e professores da rede municipal e estadual de ensino. 


\section{NÚMEROS DISPONÍVEIS}

Fragmentum é uma publicação do Laboratório Corpus. A primeira série de artigos será constituída de textos apresentados no II Seminário Corpus. Os três eixos temáticos discutidos são a memória, a história e a identidade.

A publicação é distribuída gratuitamente aos participantes do Laboratório Corpus durante os Seminários de Trabalho que ocorrem mensalmente no Centro de Educação, Letras e Biologia.

Eis os números disponíveis:

\section{Fragmentum 1}

História, memória e mito no Romanceiro da Inconfidência

Sílvia Carneiro Lobato Paraense

\section{Fragmentum 2}

Memória da escrita e escrita da memória Marcia Cristina Corrêa

A fim de obter maiores informações, entre em contato com Mirian de Paula, através do e-mail: mibrum@uol.com.br. 